\title{
Zirconium Coprecipitation Method for Fluorometric Determination of ppt Level Selenium(IV) and Selenium(VI) in Groundwaters
}

\author{
Yuzo Tamari, Rie Hiral, Haruo Tsujl and Yuzuru Kusaka \\ Department of Chemistry, Faculty of Science, Konan University, \\ Okamoto, Higashinada, Kobe 658
}

\begin{abstract}
A new coprecipitation method for the fluorometry of selenium(IV) and selenium(VI) in groundwaters has been developed. Selenium(IV \& VI) were coprecipitated with zirconium(IV) hydroxide from 1 I of groundwater at $\mathrm{pH}$ 8. Without aging, the precipitate was centrifuged and then dissolved in hydrochloric acid. Selenium(IV) was determined by the usual fluorometry with 2,3-diaminonaphthalene (DAN). From another portion of the same groundwater, selenium(IV) and selenium(VI) were determined by the DAN fluorometry after reducing all the selenium to selenium(IV) by $6 \mathrm{M}$ hydrochloric acid treatment. The concentration of selenium(VI) was obtained by subtracting that of selenium(IV) from the total for selenium. The established method is rapid and convenient (taking about $2 \mathrm{~h}$ for 10 sample treatments) because the precipitate is easily separable without aging. The method is able to detect nanogram amounts of selenium, for use with high purity zirconium reagents (containing $0.003 \mathrm{ng}$ Se in $1 \mathrm{mg}$ of $\mathrm{Zr}$ ) and with two sub-closed glass vessels to avoid any contamination.
\end{abstract}

Keywords Speciation, selenium, coprecipitation, zirconium hydroxide, 2,3-diaminonaphthalene, fluorometry, groundwaters

Selenium concentrations in natural waters are very low, being ppt levels in sea- and river-waters. ${ }^{1}$ Accordingly, selenium should be preconcentrated by an appropriate method prior to the determination of selenium. Coprecipitation has been generally used for the concentration of trace amounts of selenium in water samples: coprecipitation with iron(III) hydroxide $^{2-4}$, which collects selectively selenium(IV) but not selenium(VI); with tellurium ${ }^{4}$, which collects selenium(VI) with a gray metallic tellurium reduced from tellurium(IV) by hydrazine sulfate; and with barium sulfate ${ }^{5}$, which collects selenium(VI) by the formation of mixed crystals barium-sulfate and -selenate. In these coprecipitation methods, however, it takes a few hours to age the precipitate, and it is necessary to separate coprecipitants such as iron from selenium, and to purify the coprecipitant to keep it free from selenium. A solvent extraction ${ }^{1}$ is a rapid and convenient method for the preconcentration of ppt levels of selenium in river- and sea-waters. In the extraction, selenium(IV), selenium(VI) and organic selenium were fluorometrically determined with a chelate extraction using 2,3-diaminonaphthalene (DAN), which selectively reacts with selenium(IV) and forms a stable piazselenol (a DAN-selenium complex). However, this extraction method is not suitable for treatments of high volumes of water samples of 1-2 l.
We have developed a new coprecipitation method for the determination of nanogram amounts of selenium in fresh waters. In this method, selenium(IV) and selenium(VI) were collected with zirconium(IV) hydroxide, which has been used as coprecipitant for both arsenic(III) and arsenic(V) ${ }^{6}$, and for phosphorus(V). ${ }^{7}$ Each concentration of selenium was determined by the DAN fluorometry, without separating the selenium from zirconium. The method was applied to 29 groundwater samples used daily for drinking water.

\section{Experimental}

\section{Reagents}

Highly pure water, distilled twice and doubly deionized, was used throughout the present work.

A standard $1000 \mathrm{mg} / 1$ stock solution of selenium(IV) was prepared as follows. Dissolve $0.1 \mathrm{~g}$ of high purity metallic selenium $(99.999 \%)$ into $2 \mathrm{ml}$ of nitric acid and $1 \mathrm{ml}$ of perchloric acid $(60 \%)$. Concentrate it on a hot-plate until white fumes of the perchloric acid appear. Add $20 \mathrm{ml}$ of $6 \mathrm{M}$ hydrochloric acid, and boil the mixture for $3 \mathrm{~min}$ to reduce all the selenium to selenium(IV). Dilute the solution with water to $100 \mathrm{ml}$.

A standard $1000 \mathrm{mg} / \mathrm{l}$ stock solution of selenium(VI) was prepared by dissolving $0.2393 \mathrm{~g}$ of sodium 
selenate in water, and then by diluting the solution to $100 \mathrm{ml}$ with water after the addition of $0.5 \mathrm{ml}$ of nitric acid.

A working solution of standard selenium(IV) and selenium(VI), containing 10-50 ng each of selenium per $1 \mathrm{ml}$, was prepared by diluting the stock solution with $0.1 \mathrm{M}$ hydrochloric acid.

A solution of EDTA-NaF (0.2 M each) was prepared by dissolving $74.5 \mathrm{~g}$ of disodium EDTA dihydrate and $8.4 \mathrm{~g}$ of sodium fluoride in water, and by diluting to $1000 \mathrm{ml}$ with water.

A zirconium $10 \mathrm{mg} / \mathrm{ml}$ solution was prepared by dissolving $35.3 \mathrm{~g}$ of zirconium oxychloride octahydrate (Wako Pure Chemical Industries, Ltd., Osaka, Japan) in water and then diluted to $1000 \mathrm{ml}$ with water.

A $0.1 \%(w / v)$ aqueous DAN solution was prepared with DAN (Dojin Chem. Labo., Kumamoto, Japan) after purifying it by the reported method. ${ }^{8}$

All other reagents and solutions were of the highest purity available, and were used without further purification.

\section{Apparatus}

A spectrofluorometer (Model 650-10S; $150 \mathrm{~W}$, xenon lamp) and a $\mathrm{pH}$ meter equipped with a glass electrode (Model $\mathbf{M}-7$ ), both from Hitachi Ltd., Tokyo, were used.

Glass vessels should be kept so as not to be contaminated with selenium and fluorescent compounds by washing the vessels with a neutral detergent, then soaking them in about $5 \mathrm{M}$ nitric acid solution for a few days. Details are described elsewhere. ${ }^{9}$

\section{Recommended procedure}

Nanogram amounts of selenium(IV) and selenium(VI) were treated in a sub-closed system using one beaker and one tube. Figure 1 shows a scheme of the system.
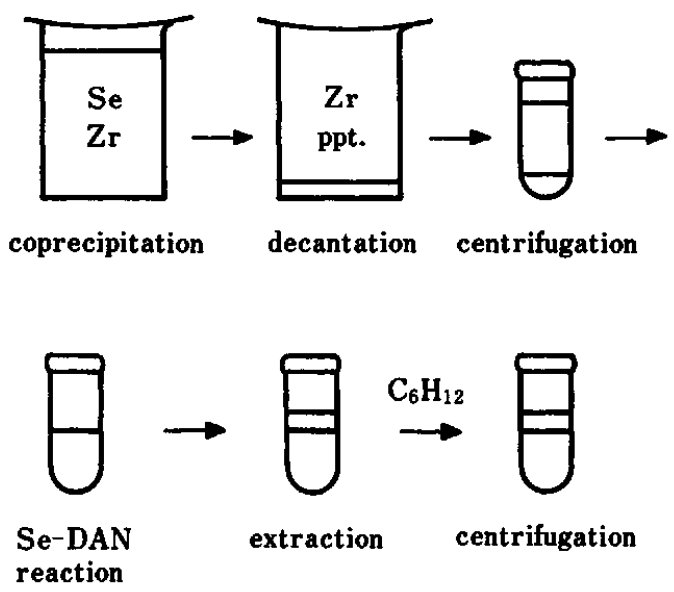

Fig. 1 Sub-closed system scheme for fluorometry of selenium.
Coprecipitation of selenium. In a beaker, take $1000 \mathrm{ml}$ of water and add about $2 \mathrm{ml}$ of concentrated hydrochloric acid to adjust the $\mathrm{pH}$ to about 1 . Add $4.5 \mathrm{ml}$ of zirconium solution and then about $2 \mathrm{ml}$ of $25 \%$ aqueous ammonia dropwise. Adjust the $\mathrm{pH}$ to 8.0 with dilute ammonia. Stir the solution containing the white precipitate for a few min, and transfer it to a $50-\mathrm{ml}$ volume of centrifugal tube with a stopper. Centrifuge the precipitate at $2500 \mathrm{~min}^{-1}$ for $5 \mathrm{~min}$, and discard the supernatant solution.

Determination of selenium(IV). Dissolve the precipitate of zirconium(IV) hydroxide in the tube with $1 \mathrm{ml}$ of $6 \mathrm{M}$ hydrochloric acid. Add $3 \mathrm{ml}$ of EDTA-NaF solution to mask the zirconium, and then add $5 \mathrm{ml}$ of a freshly purified DAN solution. Adjust the resulting solution to $\mathrm{pH} 1.0$ with a saturated sodium acetate solution and with $6 \mathrm{M}$ hydrochloric acid. Make up the solution to about $30 \mathrm{ml}$ with water, and warm the tube covered with its cap at $50^{\circ} \mathrm{C}$ for $15 \mathrm{~min}$ in a thermostatically controlled water bath. Cool the tube in ice water, and then add $10 \mathrm{ml}$ of cyclohexane. Shake the mixture for $5 \mathrm{~min}$ to extract piazselenol (selenium-DAN complex) into the cyclohexane layer. Centrifuge the tube at $2500 \mathrm{~min}^{-1}$ for $5 \mathrm{~min}$ to separate the organic layer. Identify the piazselenol by comparing the fluorescent spectrum of a standard with that of a sample, which was recorded in the wavelength range of $400-600 \mathrm{~nm}$ at excitation of $375 \mathrm{~nm}$. Measure the relative fluorescence intensities of piazselenol in the standard and in the sample at the 520 $\mathrm{nm}$, which is the peak for piazselenol fluorescence. The detection limit for selenium was $0.05 \mathrm{ng}$ in $10 \mathrm{ml}$ of cyclohexane.

Determination of selenium(VI). Dissolve another precipitate of zirconium(IV) hydroxide in the centrifugal tube with $1 \mathrm{ml}$ of $6 \mathrm{M}$ hydrochloric acid. Transfer the solution to a $50-\mathrm{ml}$ velume beaker with $4 \mathrm{ml}$ of $6 \mathrm{M}$ hydrochloric acid. Boil the beaker covered with a watch glass on a hot-plate for about $3 \mathrm{~min}$ to reduce all the selenium to selenium(IV). Cool and transfer the solution to the original tube. [Alternative reduction procedure: Dissolve the zirconium precipitate in the tube with $5 \mathrm{ml}$ of $6 \mathrm{M}$ hydrochloric acid, and stand the tube covered with its cap in a boiling water bath for 10 min, in order to reduce to selenium(IV). This procedure is recommended in any atmosphere in which contamination from selenium may appear.] Determine the concentration of total selenium in the solution by the same treatment as mentioned above for selenium(IV). Obtain the concentration of selenium(VI) by subtracting that of selenium(IV) from the total selenium amount.

\section{Results and Discussion}

Effect of reaction temperature on the reduction of selenium $(V I)$

In acidifying the selenium(VI) solution with a 
concentrated hydrochloric acid, it was found that a part of the selenium had been reduced to selenium(IV). This reduction was due to an exothermic reaction with the acid. Figure 2 shows the reduction of selenium(VI) to selenium(IV) by $6 \mathrm{M}$ hydrochloric acid treatments for $10 \mathrm{~min}$. Since about $20 \%$ of selenium(VI) was reduced even at room temperature, it is of importance not to drop the concentrated hydrochloric acid in the preparation of working solutions of standard selenium(VI).

\section{Effect of EDTA-NaF on the masking of zirconium}

Zirconium should be masked with EDTA-NaF,

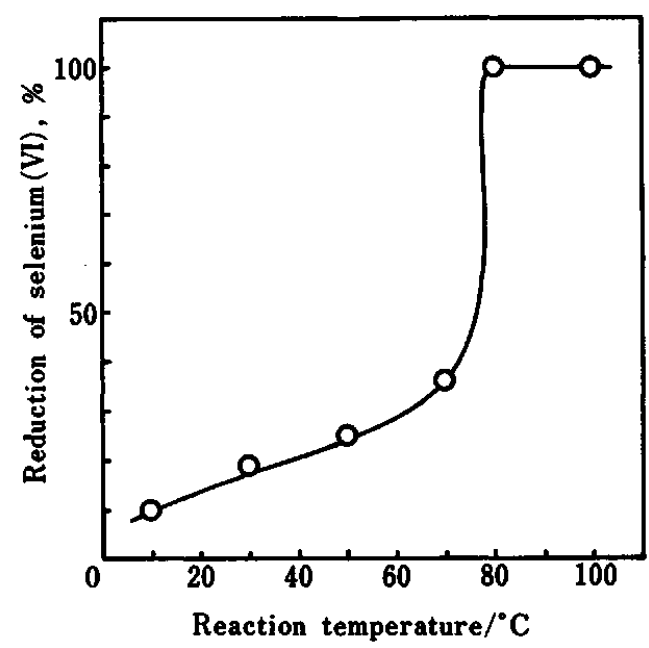

Fig. 2 Effect of reaction temperature on the reduction of selenium(VI) to selenium(IV). In $6 \mathrm{M}$ hydrochloric acid solution, $50 \mathrm{ng}$ of selenium(VI) was reduced for $10 \mathrm{~min}$.

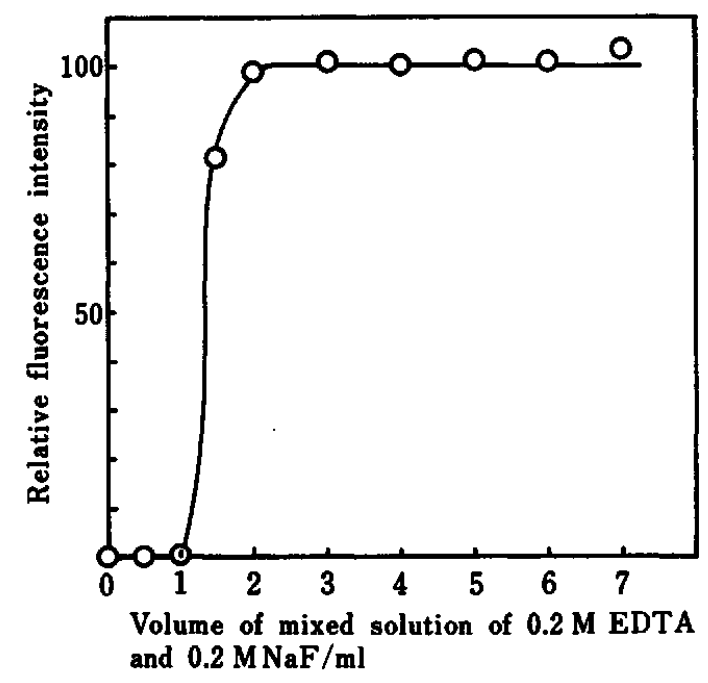

Fig. 3 Effect of EDTA-NaF to mask zirconium. Selenium(IV) $50 \mathrm{ng}$ was determined byn DAN fluorometry in the presence of $\mathbf{4 5} \mathrm{mg}$ of zirconium and of definite volumes of the EDTA-NaF solutions. since selenium(IV) could not react with DAN in the presence of zirconium, probably due to formation of a stable complex of zirconium(IV) selenite. Figure 3 shows the masking effect for zirconium. It was found that $45 \mathrm{mg}$ of zirconium coexisting with selenium did not interfere with the fluorometry of selenium, when more than about $2 \mathrm{ml}$ of EDTA-NaF solution was added. More than $4 \mathrm{ml}$ of the solution, however, is not recommended, because the excess addition brought about the white precipitate of the EDTA-NaF, and disturbed the next extraction procedure of selenium. Accordingly, the addition of $3 \mathrm{ml}$ of the EDTA-NaF solution was preferred in this work.

Effect of amounts of zirconium on the coprecipitation of selenium

As is seen in Fig. 4, selenium(IV) and selenium(VI) were almost quantitatively coprecipitated from $1000 \mathrm{ml}$ of water at $\mathrm{pH} 8$ by the formation of zirconim(IV) hydroxide, in the use of $40-50 \mathrm{mg}$ as zirconium. In this work, therefore, we decided on the addition of 45 $\mathrm{mg}$ of zirconium. A negligible amount of selenium, $0.14 \pm 0.04(n=3) \mathrm{ng}$, was contained in the $45 \mathrm{mg}$ of zirconium.

\section{Effect of $\mathrm{pH}$ on the coprecipitation of selenium}

Selenium(IV) and selenium(VI) were quantitatively recovered from water at pH 6 to 9, as shown in Fig. 5. From this results, the coprecipitation at $\mathrm{pH} 8$ was recommended.

\section{Analytical recovery of selenium}

Table 1 lists recovery of selenium(IV) and selenium(VI) in the recommended procedure. Almost $100 \%$ of selenium(IV) and selenium(VI) added were recovered from a distilled water sample and also from a

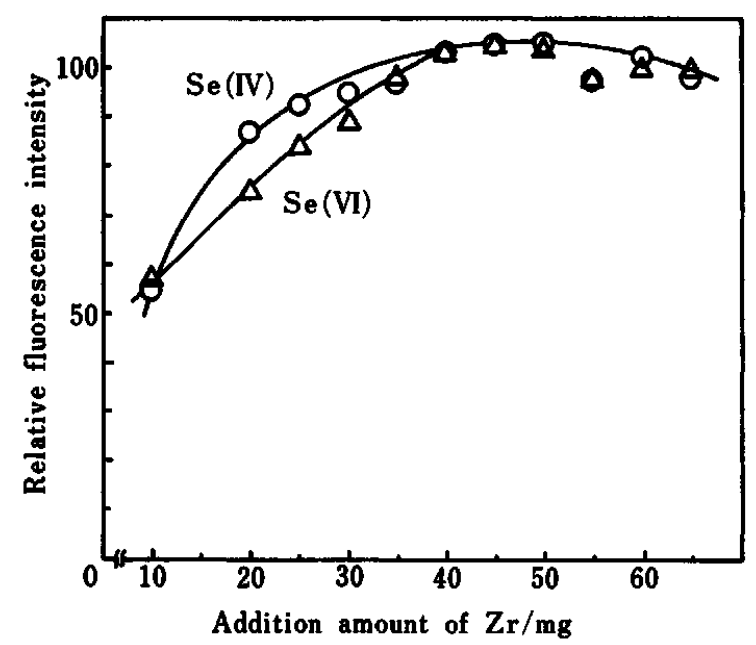

Fig. 4 Effect of amounts of zirconium on coprecipitation of selenium. Selenium(IV) $50 \mathrm{ng}$ or selenium(VI) $50 \mathrm{ng}$ was coprecipitated from $1000 \mathrm{ml}$ of water at $\mathrm{pH} 8$. 


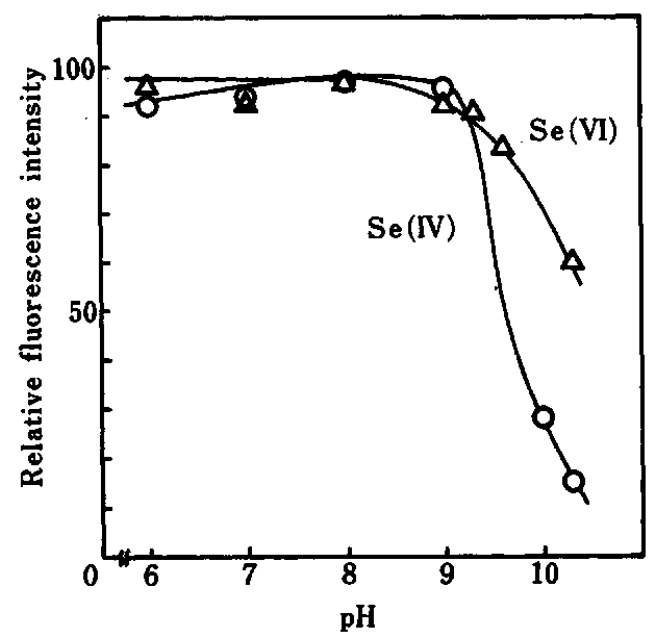

Fig. 5 Effect of $\mathrm{pH}$ on coprecipitation of selenium. Selenium(IV) $50 \mathrm{ng}$ or selenium(VI) $50 \mathrm{ng}$ was coprecipitated with $45 \mathrm{mg}$ of zirconium from $1000 \mathrm{ml}$ of water.

groundwater sample collected from the Rokko granitic area. The relative standard deviation for the recovery was in the range of approximately $1-5 \%$ for both the selenium values.

\section{Concentration of selenium in groundwater}

The established fluorometry was applied to groundwater samples collected mainly from an agricultural area, Hase-tani, Kobe, where the groundwaters are pumped out of shallow wells (about 5-15 $\mathrm{m}$ depth) and are daily used for drinking water. This area belongs geologically to the Osaka-group layer which is diluvial soils and old lake deposits of $c a .2$ million years ago. Table 2 summarizes results of the groundwater analyses; concentrations of various chemical species were determined by usual chemical methods. ${ }^{10}$ As is indicated in Table 2, the concentrations of selenium(IV) found were higher than those of selenium(VI). Therefore, most selenium exists in the groundwaters as inorganic selenite rather than selenate. In addition, the existence of organically-complexed selenium could not be supported since each fluorescence spectrum detected in the groundwaters was identified to the standard piazselenol, and since the spectrum was not interfered with by any other fluorescent compounds.

Table 3 shows the coefficient of correlations between selenium and other species for 29 groundwater samples listed in Table 2. There were positive correlations in the following chemical species; 0.72 for $\mathrm{Se}$ (IV) vs. K, $0.73^{*}$ for $\mathrm{Se}(\mathrm{IV})$ vs. $\mathrm{SO}_{4}$, and 0.70 for $\mathrm{Se}(\mathrm{VI})$ vs. $\mathrm{Mg}$. Accordingly, selenium(IV) and selenium(VI) seems to be derived from the decomposition of biological compounds such as planktons and plants (chlorophyls) because of old lake deposits of this area, or from
Table 1 Recovery of selenium(IV) and selenium(VI) from distilled- and a ground-water sample

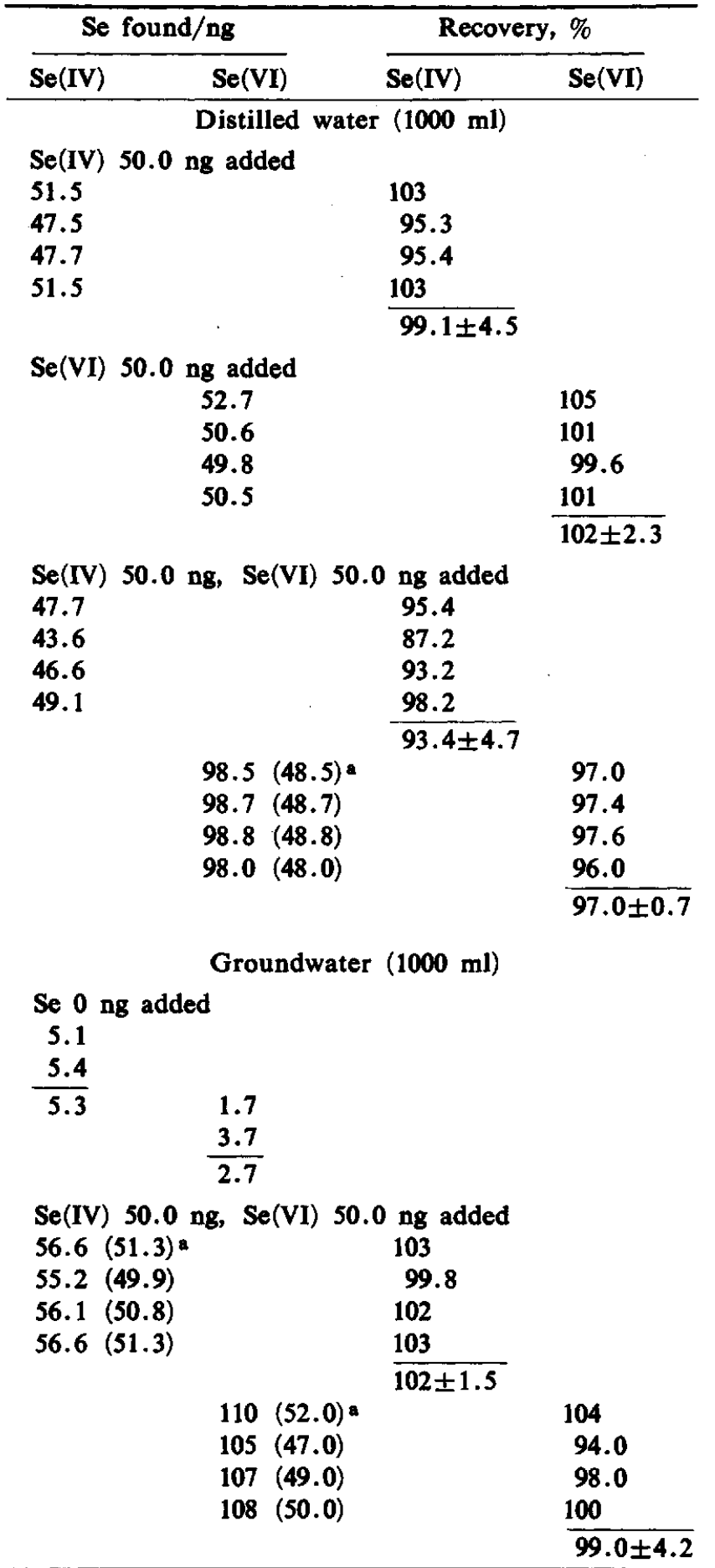

a. Values in parentheses are subtracted ones.

potash manure added in agriculture to soils.

Financial support from the Ministry of Education, Science and Culture, Japanese Government is gratefully acknowledged. 
Table 2 Analytical values of selenium and other species dissolved in groundwaters

\begin{tabular}{|c|c|c|c|c|c|c|c|c|c|c|c|c|c|c|c|c|c|c|}
\hline & & \multirow{2}{*}{ ond.a } & \multicolumn{12}{|c|}{ ppm } & \multicolumn{2}{|c|}{ ppb } & \multicolumn{2}{|c|}{ ppt } \\
\hline & & & D.0.b & E.R.c & $\mathrm{Ca}$ & $\mathbf{M g}$ & $\mathbf{N a}$ & $\mathbf{K}$ & $\mathrm{HCO}_{3}$ & $\mathrm{Cl}$ & $\mathrm{SO}_{4}$ & $\mathrm{PO}_{4}$ & $\mathrm{SiO}_{2}$ & CODd & $\mathbf{N H}_{4}-\mathrm{N}$ & $\mathrm{NO}_{2}-\mathrm{N}$ & $\mathrm{Se}$ (IV) & $\mathrm{Se}(\mathrm{V}$ \\
\hline 1 Miki & 6.5 & 2 & 10.1 & 81 & 7.0 & 3.0 & 13.3 & 9.9 & 32.9 & 3.4 & 19.4 & 4.1 & 36 & 0.7 & N.D. & 0.02 & 20.3 & 0.5 \\
\hline 2 Miki & .0 & & & 307 & 35.8 & 21.8 & 19.0 & 10.4 & 46.7 & 8.9 & 97.3 & & 30 & & T.D. & 2.3 & 54.6 & N.D. \\
\hline 3 Miki & .1 & 2 & & 662 & 13.9 & 8.1 & 9.5 & 15.4 & 35.7 & 6.0 & 27.6 & 2 & 8 & & J.D. & & 0.7 & 1.5 \\
\hline 4 Miki & 6.2 & & & 99 & 11.8 & 4.0 & 8.7 & 5 & 41. & 3.9 & 13.2 & 1.4 & 19 & & N.D. & 6.9 & 18.6 & 4.2 \\
\hline 5 Miki & 6.3 & & & 120 & 8.3 & 4.5 & 16.2 & 8.0 & 23. & 5.8 & 14.1 & 0 & 24 & & N.D. & 1.4 & 5.7 & 5.5 \\
\hline 6 Miki & 6.4 & & & 15 & 7.1 & 6.3 & 31.5 & 21.6 & 39. & 11 & 21 & & 6 & & J.D. & N.D. & 41.3 & 0.5 \\
\hline $7 \mathrm{~K}$ & 6.1 & & & & 8.1 & 10.1 & 20.2 & 4 & & 9.1 & 16. & & 5 & & .D. & 0.02 & 5.2 & 5.1 \\
\hline $8 \mathrm{~K}$ & 7.6 & 210 & & 15 & 15.9 & 12.5 & 19 & 8 & & 6.3 & & & 1 & & & N.D. & .5 & 9.3 \\
\hline $9 \mathrm{Ko}$ & 6.8 & & & $2 \pi$ & 14.2 & 11.6 & & 8 & 87. & 13 & & & & & & & & .6 \\
\hline $\mathbf{O} \mathbf{K}$ & 6.9 & & & & 3.9 & 11.0 & & & & & & & & & D. & & & .1 \\
\hline e & 7.1 & 8 & & 0 & 3 & & & & & & & & & & & & & .6 \\
\hline & 7.6 & & & & & & & & & & 14.8 & & & & & & & 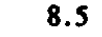 \\
\hline & 5. & & & & & & & & & & & & & & & & 1 & D \\
\hline & 5. & & & & & & & & & & & & & & & & 3 & .5 \\
\hline & 5. & & & & & & & & & 2 & & & & & D. & & .7 & 12.3 \\
\hline 1 & 5. & & & & & 27.7 & & & & 12 & & & & & D. & & .9 & .9 \\
\hline 71 & 6.4 & & & & 27.1 & & & & 58.0 & 18 & & & & & D. & & .2 & .1 \\
\hline $18 \mathrm{I}$ & 6.6 & & & & 15.6 & & & & 41. & & & & & & D. & & 2.8 & 0.1 \\
\hline $19 \mathrm{~K}$ & 7. & & & 212 & 16.0 & 3.6 & 16. & 2.1 & 43.1 & 9.3 & 12. & & & & N.D. & & 11.4 & 1.7 \\
\hline 20 Kobe & 7.3 & & & 197 & 12.6 & 3.9 & 19. & 1.3 & 32.7 & 14 & 23. & 0.7 & & & N.D. & N.D. & 0.3 & 2.7 \\
\hline 21 Kobe & 7.3 & & & 16 & 9 & 2.8 & 14. & 1. & 40.1 & 7. & 15. & 0. & & & N.D. & N.D. & 1.6 & 1.5 \\
\hline $22 \mathrm{~K}$ & 7.3 & & & 169 & 10.4 & 2.5 & 13. & & 42. & & & 0.6 & 46 & & N.D. & N.D. & 0.5 & 0.7 \\
\hline $23 \mathrm{~K}$ & 7.1 & 10 & & 161 & 9.3 & 3.5 & 14.2 & 1.5 & 33.9 & 9.1 & 12.8 & 0.5 & 44 & N.D. & N.D. & N.D. & 2.7 & 0.7 \\
\hline 24 Kobe & 7.1 & 101 & & 177 & 9.6 & 3.7 & 13.0 & 1.4 & 38.1 & 6.5 & 11.3 & 1.0 & 46 & & N.D. & & 1.4 & 1.3 \\
\hline 25 Kobe & 7.1 & 142 & 13.0 & 181 & 11.2 & 5.5 & 17.3 & 2.1 & 21.8 & 12 & 25.0 & 0.2 & 36 & N. & 0.2 & N.D. & 4.5 & N.D \\
\hline obe & 7.0 & 166 & & 231 & 16.7 & 9.7 & 12.7 & 3.2 & 47.7 & 11 & 23.3 & N.D. & 27 & N.D. & 0.2 & & 4.5 & N.I \\
\hline obe & 6.9 & 142 & 10.4 & 205 & 16.0 & 5.8 & 12.5 & 4.0 & 48.9 & & 20.0 & & 4 & 0. & 0.4 & & 6.7 & 0.6 \\
\hline 28 Kobe & 7.0 & 149 & 10.7 & 206 & 13.9 & 6.7 & 12.3 & 1.8 & 36.7 & 9.6 & 19.0 & 0.2 & 42 & 0.3 & 0.2 & & 3.4 & 0.7 \\
\hline & 6.9 & प) & 14.3 & 130 & 10.8 & 3.7 & 10.9 & 1.0 & 31.9 & 0.3 & 17.0 & 0.1 & 50 & 0.4 & IV.D. & M. & 1.1 & 0.8 \\
\hline
\end{tabular}

a. Conductivity, $\mu \mathrm{S} / \mathrm{cm}$ at $18{ }^{\circ} \mathrm{C}$. b. Dissolved oxygen. c. Evaporated residue. d. Chemical oxygen demand. N.D. Not detected. Groundwater samples No. 1-16 and No. 17-29 were collected on Oct. 6 and on Nov. 26, 1986, respectively.

Table 3 Coefficient of correlations between concentrations of selenium and other ions dissolved in groundwaters $(n=29)$

\begin{tabular}{lrr}
\hline & Se(IV) & Se(VI) \\
\hline pH & -0.23 & -0.33 \\
Cond. & 0.42 & 0.61 \\
D.O. & -0.59 & -0.25 \\
E.R. & 0.17 & 0.05 \\
$\mathrm{Ca}$ & 0.33 & 0.12 \\
$\mathrm{Mg}$ & 0.16 & 0.70 \\
$\mathrm{Na}$ & 0.22 & 0.44 \\
$\mathrm{~K}$ & 0.72 & 0.12 \\
$\mathrm{HCO}$ & 0.23 & 0.12 \\
$\mathrm{Cl}$ & -0.10 & 0.06 \\
$\mathrm{SO}_{4}$ & 0.73 & -0.24 \\
$\mathrm{PO}_{4}$ & 0.43 & -0.28 \\
$\mathrm{SiO}_{2}$ & -0.47 & -0.36 \\
$\mathrm{COD}$ & 0.48 & 0.22 \\
\hline
\end{tabular}

\section{References}

1. Y. Nakaguchi, K. Hiraki, Y. Tamari, Y. Fukunaga, Y. Nishikawa and T. Shigematsu, Anal. Sci, 1, 247 (1985).

2. Y. K. Chaw and J.P. Riley, Anal. Chim. Acta, 33, 36 (1965).

3. K. Hiraki, O. Yoshii, H. Hirayama, Y. Nishikawa and T. Shigematsu, Bunseki Kagaku, 22, 712 (1973).

4. O. Yoshii, K. Hiraki, Y. Nishikawa and T. Shigematsu, Bunseki Kagaku, 26, 91 (1977).

5. K. Hiraki, Y. Nishikawa, O. Yoshii and S. Gohda, Rikogaku Kenkyu Hokoku in Kinki Univ., No.10, 17 (1975).

6. H. Tsuji, K. Nishimura, Y. Tamari and Y. Kusaka, Bunseki Kagaku, 33, 43 (1984).

7. T. Kubota, T. Ueda and T. Okutani, Brunseki Kagaku, 35, 75 (1986).

8. Y. Tamari, Bunseki Kagaku, 33, E115 (1984).

9. Y. Tamari, S. Ohmori and K. Hiraki, Clin. Chem., 32, 1464 (1986).

10. Nihon Bunseki Kagakukai Hokkaido-shibu, "Mizu no bunseki”, p. 175, Kagakudojin Co., (1985). 